\title{
FELIPE II Y LA CONQUISTA DE RELIQUIAS POR LOS TERCIOS DE FLANDES: EL EJEMPLO DE LEIDEN (1570-1574)
}

\author{
POR \\ FÉLIX A. FERRER GARCÍA \\ Universidad Nacional de Educación a Distancia (C.A. Ávila) \\ Institución "Gran Duque de Alba"
}

\section{RESUMEN}

La concepción patrimonial y el inflamado ímpetu religioso de Felipe $\mathrm{II}$, en el marco de la compleja política exterior del siglo XVI, provocaron la presencia de las tropas castellanas en numerosos campos de batalla europeos. Durante su gobierno el rey contempló la creciente hostilidad internacional, bien por factores estratégicos, bien por un no disimulado afán imperialista, sin olvidar algunos elementos ideológicos, pues el monarca se consideraba defensor de la cristiandad. Los Tercios de Flandes, con el Gran Duque de Alba, ejercitaron su función militar, pero también actuaron como buscadores, acopiadores y custodios de numerosas reliquias depositadas en los territorios europeos septentrionales.

\section{PALABRAS CLAVE}

Reliquias; Herejía; Religiosidad; Milagros; Superstición; Tercios de Flandes; Siglo XVI; Gran Duque de Alba; Felipe II.

PHILIP II AND THE CONQUEST OF RELICS FOR THE "TERCIOS" OF FLANDERS: THE EXAMPLE OF LEIDEN (1570-1574)

\section{ABSTRACT}

The patrimonial principles and the exaggerated religious beliefs of Phillip II of Spain, placed in the complex foreign affairs of the 16th 
century, led to the presence of the castilian troops in many european battlefields. Phillip II had to cope with a raising international hostility, not only due to strategic reasons but also to his clear imperialist ideas. But we can't avoid some ideological statements because the King considered himself as the true protector of Christianity. The Spanish Tercios, and specially the Duke of Alba, developed military purposes but they were also finders and guardians of the numerous relics from the northern european territories.

\section{KEY WORDS}

Relics; Heresy; Religion; Miracles; Superstition; Spanish Tercios; 16th century; Duke of Alba.

Recibido/Received

29-05-2009

Aceptado/Accepted

$18-05-2014$

Se ha insistido tradicionalmente en resaltar el papel militar del tercer duque de Alba ocultando a veces otros perfiles historiográficos más variados pero, de igual modo, atractivos para comprender los tumultos políticos y religiosos de los Países Bajos. Frente a una reducida interpretación que contraponía la sublevación popular a la opresión religiosa de los españoles, algunos estudios de los últimos años matizan, sobre todo, la radicalización de la crisis por motivos económicos y tributarios. Sin embargo, en este artículo se expondrán algunos aspectos relacionados con el ambiente contra-reformista del concilio de Trento, el papel de don Fernando Álvarez de Toledo en el control de los asuntos eclesiásticos y religiosos hasta su sustitución, en 1573, por Luis de Requesens, y, por último, el fervor religioso de Felipe II, repleto a veces de matices supersticiosos con el culto desaforado a las reliquias y su confianza en las acciones milagrosas.

Al margen de la creación de una infraestructura militar sumamente compleja en Flandes, la propaganda monárquica insistía en asimilar las victorias bélicas con los triunfos espirituales, la represión implacable con la obligación del rey de mantener la fe católica y, finalmente, la vida de algunos soldados con la recuperación de las santas reliquias dispersas por esos territorios septentrionales proclives a la herejía.

Anotaba el fraile jerónimo José de Sigüenza "la codicia con que las mandaba buscar por todo el mundo", "la avaricia con que las guardaba", dando el monarca órdenes a clérigos, militares y diplomáticos para salvaguardar esos tesoros humanos que, por otra parte, procuraban casi siempre una beneficiosa acción taumatúrgica. En ocasiones, el prestigio 
militar, o la heroicidad del soldado, desde la óptica hispánica, se expresaba no tanto por las conquistas territoriales, el número de muertos - las oportunidades de supervivencia como por las posesiones simbólicas que se lograban precisamente en unos instantes en que la soldadesca se caracterizaba por su inmoralidad y corrupción, por las deudas, los juegos, malas mujeres, etc... ${ }^{1}$

En ese contexto, los protestantes contemplaban desde mediados del siglo XVI las oscuras intenciones de un rey que trataba de tiranizar a la cristiandad.

\section{EL SENTIMIENTO RELIGIOSO EN TORNO A LAS RELIQUIAS}

En 1571, el cardenal Alejandrino, legado del papa Pío V, confirmó al rey la entrega de unos restos de las Once Mil Vírgenes (Vndecim Millium Virginum), concediendo durante tres años indulgencias pro remedio animae. ${ }^{2}$ Algunos restos de santa Úrsula llegaron a la lipsanoteca escurialense. Años después, reinando el piadoso Felipe III, se incorporaron al relicario urbano de Ávila dos cabezas pertenecientes a los santos de la Legión Tebana de san Mauricio, víctimas en las Galias de las persecuciones del emperador Maximiano, y el fragmento de un largo hueso de una de las mártires, las que sufrieron tormentos por los hunos en el siglo IV, representadas particularmente por la princesa asaetada en Colonia en el año 383. La trascripción de un par de pergaminos procedentes de la casa parroquial de la basílica de los Santos Mártires Vicente, Sabina y Cristeta de Ávila permite despejar algunos interrogantes. ${ }^{3}$

1 Vid. Ferrer García, F. A. 2009. "Entre el ardor guerrero y el fervor religioso: la vida del capitán Cristóbal de Castro (1545-1585)", en G. del Ser Quijano (ed.), Congreso $V$ Centenario del nacimiento del III\#Duque de Alba Fernando Álvarez de Toledo. Actas: 547-556. Ávila: Institución "Gran Duque de Alba"-Diputación de Salamanca.

${ }^{2}$ Archivo Catedralicio de Ávila (ACAv). Pergaminos. Doc. n. ${ }^{\circ}$ 160. Perg., $260 \times 380$ (1571, octubre, 21. Madrid). A finales del siglo XV se produce la lectura errónea de la abreviatura XI MV " "once mártires y vírgenes". La leyenda quedaba tardíamente confirmada tras el descubrimiento en 1155, en Colonia, de una gran cantidad de osamentas atribuidas a Úrsula y sus compañeras. Vid. Tervarent, G. 1931. La légende de Sainte Ursule dans la littérature et dans l'art du Moyen Âge. Paris: Éditions G. van Oest.

${ }^{3}$ Archivo Parroquial de San Vicente de Ávila (APSV). Copia del notario Liberto Melyn sobre la donación de la abadesa del monasterio del Huerto a Gonzalo de Henao de algunas reliquias de san Ambrosio, san Gregorio y las Once Mil Vírgenes, confirmándose dicha donación a doña Juana de Lunar (1609, septiembre, 5 / 1618, septiembre, 5. Wesssaliae), pergamino, $280 \times 300$, latín, sello de papel sobre cera verde. Copia del notario Liberto Melyn sobre la 
Unas intervenciones de Gonzalo de Henao, mayordomo de artillería, y Gonzalo Guerra de Vega, contador en Flandes de Felipe III, en nombre de doña Juana de Lunar, azafata de la infanta, permitieron la llegada a la ciudad castellana de los restos tebanos y otros con autorización de Wilhemus Aberencastelet, obispo de Tréveris y decano de la colegiata de San Pablo.

El notario Liberto Melyn dio fe en 1609 de la cesión de unas piezas mayores y menores de las Once Mil Vírgenes, además de unos restos cortados o aserrados, en una sesión celebrada el 5 de septiembre, de los santos Ambrosio y Gregorio, depositados hasta ese momento en el monasterio del Huerto de Wesalia, monasterium sancti moniarum Horta Beati Marie Virginia, in ciuitate Wesaliensi, ducatus Cluniaec [in Ducatus Clivensi], cuya abadesa era Cunegunda de Rhee. En 1611 se entregaron las otras reliquias, las cabezas de los tebanos, si bien en el pergamino en cuestión se mencionan unum caput et duo ossa ex societate sanctorum thebanorum...

Parte de las anteriores reliquias aparecieron sorpresivamente en la cripta de la Virgen de la Soterraña, el subsuelo de la basílica abulense de San Vicente y sus hermanas mártires, cuando en una cajonera del altar barroco localicé en abril de 1999 unos huesos que no estaban catalogados en los pormenorizados relatos de Gil González Dávila, Bartolomé Fernández Valencia o José Tello Martínez, mucho menos en las líneas de los escritores contemporáneos.

En tinta se especificaba que las cabezas correspondian a los mártires tebanos y el hueso a una de las vírgenes. Unos años después, en 6 de abril de 2002, esas osamentas fueron depositadas por el prelado de Ávila don Adolfo González Montes bajo la mesa del presbiterio, acompañadas de otros restos pertenecientes a san Paciente de Lyon y san Máximo de Turín.

Agigantado el acontecimiento, al día siguiente las anónimas reliquias se convirtieron para la prensa local en las de san Mauricio y santa Úrsula. ${ }^{4}$

Antes (y ahora) las reliquias parecían constituir unos objetos de veneración y salvación. Compradas, vendidas, robadas y trasladadas,

donación hecha por el deán de San Paulino de Tréveris de la cabeza y hueso de los mártires de la Legión Tebea, con atestación del mismo escribano realizada a doña Juana de Lunar en Bruselas (1611, octubre, / 1614, abril, 14. Tréveris), pergamino, 2 hoj. in fol., sello de cera verde pendiente.

${ }^{4}$ Vid. El Diario de Ávila, 7 de abril de 2002. 
entraban en el mundo de la reciprocidad entre el plano real y el de la divinidad, señalaban un prestigio social y religioso para quien las poseía.

Aunque en la plena Edad Media los restos santificados acentuaban una sujección de los fieles hacia los santos, y viceversa, con un recorrido cultual mágico que no encontraba una oposición demasiado seria por parte de las instituciones eclesiásticas, ${ }^{5}$ a partir del siglo XVI con la Reforma y la expansión del luteranismo, anabaptismo y calvinismo se inicia una modificación del discurso teológico y, gradualmente, se condenan algunas prácticas en torno a los despojos de los individuos santos, pues, en la práctica, los sentimientos encontrados en torno a unos restos humanos desconocidos, escasa o malamente autentificados encerraban una forma de idolatría, al igual que ocurría con la exagerada devoción de ciertas imágenes.

Pero, al sur, iniciándose el concilio de Trento, los textos eclesiásticos y literarios lanzaban a las reliquias a su papel de recreadoras de vida, el poder de los santos, subrayándose también el fin de toda vida corporal. Eran custodiadas en iglesias y monasterios, amparaban a las cofradías, calmaban los temores: san Roque y san Sebastián protegían de la peste, santa Apolonia era invocada contra el dolor de muelas, san Antonio abad ahuyentaba al demonio y los enfermos de gota rezaban a los santos Andrés y Mauro. Las buenas cosechas contaban con la protección de san Isidro Labrador, mientras que, en momentos inestables, santa Bárbara era invocada contra los truenos y santa Úrsula en tiempo de guerra. Constituían también las reliquias garantías para el más allá.

En ese marco de polarización religiosa derivada del concilio tridentino, las ocupaciones militares de Álvarez de Toledo se confundirán en muchos momentos con la recuperación de reliquias en las ciudades flamencas inclinadas hacia la revuelta iconoclasta. Hombre de estado, militar forjado en numerosas batallas, individuo impregnado de los gustos palaciegos y artísticos procedentes de Italia, el tercer duque de Alba eliminó cualquier tipo de disidencia religiosa, vaciando iglesias y monasterios de algún recuerdo santo que pudiera caer en manos de los herejes.

Una desertización del relicario flamenco que, por otra parte, obsesionó al monarca Felipe II, de manera que en los años setenta un

${ }^{5}$ Geary, P.J. 1979. "La coercition des saints dans la pratique religieuse médiévale", en IV Colloque de I'Institut d'Études Medievales de l'Université de Montréal : 512-522. Montréal : Université de Montréal. Thomas, K. 1991. Religion and the decline of magic. Studies in popular beliefs in Sixteenth and Seventeenth-century England: 27-57. London: Penguin Books. 
buen número de reliquias son conquistadas por el duque de Alba y el capitán Alfonso de Sotomayor en Bruselas, Colonia y Augsburgo.

Al menos tres de las codiciadas piezas llegaron a Alba de Tormes (Salamanca) el día 17 de junio de 1574. Se buscaban con afán los restos de los mártires de la Legión Tebana para enviarlos desde Colonia a la condesa de Uceda. ${ }^{6}$ Se multiplicaban los hallazgos sorprendentes en todos los rincones del mundo católico, particularmente en Italia.

"En el año 1583, en el pontificado de Gregorio XIII, fueron hallados los sanctos mártires Abundio y Abundançio en la yglesia de San Cosme y San Damián, y trasladados el año delante de 1584 a la yglesia de Sancta María de Astali, de la Compañía de Jesús, cuya obra començó el cardenal Farnesio, año de 1568".?

Se hacían prospecciones arqueológicas para localizar los huesos santos en las catacumbas romanas de San Calixto, "inventándose" (descubriéndose) en 1594 el cuerpo íntegro de san Vidal (Vitalis), luego concedido por el papa al obispo de Cartagena, Sancho Dávila y Toledo, a instancia de su primo el embajador en Roma y gran duque de Toscana. ${ }^{8}$ Estas últimas reliquias fueron recibidas por el cabildo abulense en junio de 1613, gracias al legado del prelado, en esos momentos en la sede de Jaén: “... propuso el señor deán cómo después del cabildo se vio la caja en que venía el cuerpo de sant Vidal estaba en buena guarda y muy deçente para ponerle en el altar mayor a uno de sus ángulos..."

${ }^{6}$ ACAv. Pergaminos. Doc. n. ${ }^{\circ}$ 169. Perg., s. XVII, 425 x 575. Informe sobre las reliquias de los mártires de la Legión Tebea enviadas a la duquesa de Uceda (1601, mayo, 28. Colonia). En efecto, esas reliquias de los compañeros de san Mauricio fueron entregadas en Colonia a don Luis de Peñaranda, comisionado por Felipe III para entregar algunas de ellas a la condesa de Uceda, doña Leonor de Guzmán, en ese año camarera de la infanta Isabel Clara Eugenia.

7 APSV. Pap., sin enc., dos piezas cosidas entre sí; probablemente la autoría se deba adjudicar al regidor abulense Luis Pacheco de Espinosa, con notas añadidas en los años setenta del siglo XVII del clérigo beneficiado Bartolomé Fernández Valencia. Discurso sobre la ynuençión del cuerpo de sant Pedro del Varco..., año de 1610, fol. 8 r.

${ }^{8}$ ACAv. Pergaminos. Doc. n. ${ }^{0} 167$ (1594, diciembre, 12. Roma). Perg., s. $\mathrm{XVI}, 360 \times 485$, sello de cera roja en caja dorada. Sobre el enorme relicario en posesión del prelado Dávila, vid. Ruiz-Ayúcar Zurdo, M. ${ }^{a}$ J. 1998. "Reliquias y relicarios. El legado de don Sancho Dávila y Toledo", en Homenaje a Sonsoles Paradinas: 231-245. Ávila: Museo de Ávila. Sanz Hermida, J. 2001. "Un coleccionista de reliquias: don Sancho Dávila y el Estudio Salmantino". Via Spiritus 8: 59-93.

9 ACAv. Actas Capitulares. Libro 39, fols. 46 v.-47 r. APSV. Discurso sobre la ynuençión..., fol. 10 r.: "Su Sanctidad Clemente octauo, por su breue dado en Roma en 17 de henero de 1595, conzedió al señor don Sancho Dávila, 
En efecto, en las últimas décadas del siglo XVI los Tercios de Flandes, al margen de su actuación militar, almacenaban esos tesoros investidos de una aureola sagrada, propagandística y agorera en un espacio geográfico en el que la situación religiosa era sumamente compleja. Se trataba, sobre todo, de asegurar el control en el tránsito de las reliquias hasta su llegada a los reinos hispánicos, pues muchas de ellas no eran lo suficientemente veneradas en unos lugares en que corrían un serio peligro "en venir a manos de los herejes, que como tan del bando del enemigo de Dios, hacen sangrienta guerra a sus santos". ${ }^{10}$

Para la mirada de los súbditos españoles de Felipe II, una herejía se instalaba cómodamente en las populosas ciudades flamencas con comunidades luteranas, anabaptistas y calvinistas. Tal situación se complicaba por el desorden en la estructura eclesiástica a la llegada del duque de Alba, pues apenas se habían aplicado algunas reformas promulgadas unos años antes, entre 1559 y 1561, es decir, la reorganización de la Iglesia en los Países Bajos con la creación de catorce nuevos obispados bajo la autoridad del primado, el cardenal Granvela.

El principal foco de tensiones había surgido entre los años 1564 y 1566. Los ideales nacionalistas se mezclaron con las consecuencias de la política religiosa dirigida por Felipe II. Tras esos desórdenes, la participación coactiva del duque de Alba pareció alcanzar algún objetivo, pero, a corto plazo, tanto la política impositiva como los frecuentes motines de un ejército escasamente remunerado imposibilitaron el apaciguamiento de las hostilidades.

De esta forma, el tercer duque no tuvo más remedio que asumir consciente y decididamente una política represiva contra la herejía y los privilegios locales de los Países Bajos, un procedimiento de actuación política planteado por el monarca que se centraba, ante todo, en el absolutismo regio y la renovación de la fiscalidad en los Países Bajos.

obispo de Jaén, el cuerpo entero de sant Vidal mártyr sacado de las cuevas y deuotísimo zimenterio de Sant Calisto en Roma, para cuya colocaçión y veneraçión su señoría haze en la sancta yglesia cathedral de esta çiudad, junto a la capilla de San Antolín, ylustre y antiguo entierro de sus padres antecesores la capilla que será de las ynsignes que estos reynos; tienen para el adorno de la qual están en su oratorio piezas e joyas inestimables el cuerpo deste sancto en vna arca de plata, otras reliquias riquísimas guarnecidas, muchas casullas y hornamentos diferentes, todo de gran valor y riqueza que en particular fe ve por la donaçión que de todo tiene fecha".

10 Sigüenza, José de. 1963 ( $1^{\text {a }}$ ed. 1595-1605). Fundación del monasterio de El Escorial: 165 (Discurso XIX). Madrid: Aguilar. 
Evidentemente, Álvarez de Toledo no puso reparos a esas prácticas coercitivas, alarmándose ante las numerosas predicaciones calvinistas en las ciudades, la reacción de los ciudadanos contra la ortodoxia católica representada por un soberano considerado extranjero y, además, la explosión iconoclasta iniciada en 1568.

Desde 1566 se habían sucedido los pillajes en iglesias y monasterios en Amberes, Brujas, Amsterdam, Leiden, Mons, Bruselas y otras ciudades. La consecuencia fue una destrucción limitada de la iconografía religiosa católica. Luteranos y demás enemigos del orden católico desmontaban y quemaban reliquias y relicarios, algo incomprensible para los meridionales europeos que ya habían asumido, como san Ignacio de Loyola, que esos restos vilipendiados y saqueados representaban pequeñas "encarnaciones", en alusión a la Encarnación del Verbo, válidas como pruebas de una santidad alcanzada a la que todas las gentes aspiraban.

"Las reliquias resultan ser, por tanto, materializaciones sensibles, localizadas y concretas de una epifanía, manifestaciones de una presencia divina que ofrecen la posibilidad de tocar, ver e incluso oler lo sobrenatural". ${ }^{11}$

Los recuerdos de santos conservados en abadías, monasterios, iglesias y catedrales corrían al parecer un serio peligro, de manera que la alternativa era procurar un acercamiento a aquellos clérigos que custodiaban algunos restos bajo su jurisdicción, o bien una propuesta más dura, la de reconquistar violentamente los despojos sagrados, las vestiduras y objetos emblemáticos antes de que fueran liquidados por los herejes flamencos.

Como católico, el de Alba compartía las obsesiones religiosas del rey, mientras que como militar puso todo su empeño en evitar cualquier concesión nacional a los súbditos de Felipe II en esos años que anunciaban un largo conflicto internacional, la Guerra de los Ochenta Años (1568-1648).

Su resentimiento crecía a medida que se alargaba su estancia en los territorios rebeldes, ampliándose su terrorífica sombra en la historiografía holandesa, particularmente en el período romántico representado por el historiador Jan Frederik Helmers (1767-1813): "Violencia, traición y engaño salidos de sus mazmorras, / habitan el

${ }^{11}$ Bouza Álvarez, J. L. 1990. Religiosidad contrarreformista y cultura simbólica del Barroco: 42. Madrid: CSIC. 
corazón de Alba, quien se apresura hacia estas tierras. I Viene acompañado por el asesinato, la coacción moral y el despotismo". ${ }^{12}$

En contraste, una visión más ecuánime, valorando en sus justos términos el complejo panorama político del siglo XVI y considerando la personalidad del duque como hombre que anteponía su férreo sentido del deber a cualquier otra consideración, se refleja en la obra de William S. Maltby, describiendo al duque de Alba como "un hombre violento, en el que de continuo hervía la ira bajo una apariencia de melancólica calma..., se mantenía en un estado de perpetuo furor que, cuando era más productivo, constituía la fuente de su enorme energía. En aquellos momentos, rodeado de herejes y criptoherejes y abandonado, según él, por el rey y la corte, esperaba y aun rogaba que se ofreciera un pretexto para hacer caer sobre la cabezas de aquellos traidores lo que él consideraba el juicio de un Dios justo". ${ }^{13}$

\section{LA CONQUISTA DE LEIDEN Y LAS RELIQUIAS DEL DIÁCONO VICENTE DE ZARAGOZA}

Desde el año 1568 algunas compañías del duque de Alba se encontraban en Leiden para prevenir un ataque por sorpresa de las fuerzas leales a Guillermo de Orange. Contaba la ciudad con una importante población defendida por baluartes, bastiones y terrenos anegados.

Unos meses antes de iniciarse el asedio definitivo de la antigua Ludgunum Batavorum (Leithis > Leyden), en la Holanda meridional, don Fernando Álvarez de Toledo, gobernador y capitán general ditionum Inferioris Germaniae patrimonialum de Felipe II, recibió del obispo Groisbeeck unas reliquias de san Vicente, parte del maxilar inferior y un diente, restos que desde tiempos inmemoriales se encontraban "mantenidos y guardados... con cuidado y con celebrado honor y reverencia" en el monasterio de Santiago (monasterij Sancti lacobi ciuitatis nostri Leodiensis) y custodiados por el abad Hermann Raue.

El prelado, Gérard de Groisbeeck, anteriormente coadjutor, luego obispo de Leiden y también de Lieja, presenció el paso de las tropas por la guerra civil desatada en torno a los años setenta del siglo XVI, siendo

12 Wessels, L.H.M. 1999. "Tirano o soberano. La imagen cambiante de Felipe II en la historiografía holandesa desde Bor hasta Fruin (siglos XVI-XIX)". Cuadernos de Historia Moderna 22: 174.

${ }^{13}$ Maltby, W.S. 2007. El Gran Duque de Alba. Un siglo de España y de Europa, 1507-1582: 379. Girona: Atalanta. 
conocido documentalmente por la publicación de una obra sobre la administración jurídica de la actual ciudad belga. ${ }^{14}$

Probablemente como prelado se presenta en torno a 1565, según las acuñaciones de unas monedas de plata grabadas en Hasselt con la siguiente leyenda: GERARDVS A. GROISBEECK EPIS. LEOD. DUX BULL - COM. LOSS. Como príncipe-obispo de Lieja era también duque de Bouillon (Luxemburgo) y conde de Loos, a orillas del Deûle, mientras que su labor como jurista fue destacada en su tiempo con una reforma que se centraba en la función burocrática del escribano o secretario de juzgado (1572), ${ }^{15}$ siendo citado por Francesco Sacchino en su obra romana sobre las gestas sacerdotales europeas. ${ }^{16}$

Partem ossis maxilaris et dentem. ¿A quién correspondían las reliquias? Aunque son entregadas al capitán general para el rey Felipe II en agosto de 1570, no parece que fueran algunos restos del dominico Vicente Ferrer, santo reverenciado por el monarca pues en su lecho de muerte se encontraba el brazo del predicador fallecido en Vannes en 1415 , además de la calavera de otro santo y una fusta de su padre Carlos V. La extravagancia del culto a las reliquias era resaltada constantemente por los cronistas e historiadores protestantes.

En el lado opuesto, en la Europa contra-reformista, mártires declarados santos y santos propiamente dichos constituían uno de los pilares de la devoción popular, impulsada en numerosos casos por las autoridades eclesiástica y monárquica. Esa devoción a los santos era prácticamente indiscutible, casi universalmente admitida, y el culto a las reliquias de mártires y confesores era aceptado con devoción.

El descuartizamiento del cuerpo santo se mostraba como la manera más eficaz para difundir las reliquias, intocables e intratables, pues entraban en el terreno de la sacralidad más evidente, la más aparatosa y tendenciosa, aquella que se situaba en el terreno puramente escatológico.

${ }^{14}$ Groisbeeck, Gérard de. 1572. Statuts et ordonnances touchant le stil et la manière de proceder et l'adminsitration de justice devant \& par les Courts \& Justices seculières du païs de Liège: In-12, 208 + (7). Liège : Henry Houius.

${ }^{15}$ Res per cardinalem Groisbeeck episcopum et principem Leodiensem et sacrum rotae auditórium iudicatae. 1670. Liège : s.n., 12.

16 "Leodij quod multis annis agrebatur tandem Collegium perfectum. Id Cardinales Episcopus Gerardus a Groisbeeck inchoatum, in Monasterio Hieronymianorum ad gymnasij opportunitatem statnerat collocare; cumque Leodiense Collegium a Card", en Historiae Societatis Iesv Pars Quinta Sive Clavdivs Tomvs Prior Avtore Francisco Sacchino Eivsdem Societatis Sacerdote..., Romae, Ex Typographia Varesij, MDCLXI, 29. 
Dada la diversidad y abundancia de reliquias en el siglo XVI se subrayaban asimismo, en el seno de la cultura popular, algunas categorías más chocantes o extravagantes. Podían ser motivo de una descripción anatómica del cuerpo puramente grotesca. Los restos del santo acercaban al creyente a la fe, pero al mismo tiempo le sumían en la apariencia de lo tenebroso, pues se trataba de entrar en contacto con los resultados de una muerte dócil o violenta, sin duda la última la más temida pero también la más ansiada por los mártires.

En cualquier caso, la propia conservación del cuerpo (entero) se tornaba imposible. Abiertamente se recogían los restos tras una carnicería post mortem, se acumulaban reliquias para encontrar una sacralidad de la privacidad en un medio religioso cada vez más polarizado en Europa y cada vez más ligado al sentido inevitable de la muerte y al tiempo heroico si el óbito se producía dentro de una normativa religiosa muy precisa.

Reinando Felipe III, el obispo de Jaén, el albense Sancho Dávila, enumeraba con detalle la "memoria de las santas reliquias que están en mi oratorio", destacando unas trescientas de Jesucristo, además de otras de la Virgen, los apóstoles y evangelistas, confesores y pontífices, vírgenes, mártires y otras santas, incluyendo en la relación "un hueso y vna muela" de san Segundo, prelado de Ávila en el siglo I, otro hueso de san Vicente, algún resto del dominico Ferrer, uno más de santa Sabina virgen y mártir y otro de santa Paula. El mismo obispo se mostraba asombrado de la actitud de los griegos frente a otras gentes en su unión con los cuerpos de los santos, olvidando que, por otra parte, la tradición judaica abominaba de cuanto hubiera estado en contacto con un cadáver, santo o no. "Quien toque a un cadáver será impuro durante siete días" (Núm. 19,11).

Así pues, unos huesos de un mártir del siglo IV aparecen sorpresivamente en Leiden, sancti Vincentij Martyris, depositados en el monasterio longissimo atque immemoriali tempore. Las noticias sobre este levita (un rango inferior al sacerdocio) se localizan en el "Himno V" de Aurelio Prudencio (Passio sancti Vincenti martyris) y en una Pasión de carácter épico, la Passio sancti ac beatissimi Vincentii levite martyris Christi, qui passus est Valentia in civitate sub Datiano preside; XI kalendas februarias. ${ }^{17}$

17 Vid. "Passio sancti ac beatissimi Vincentii levite martyris Christi, qui passus est Valentia in civitate sub Datiano preside; XI kalendas februarias", en Pasionario Hispánico. II Textos. 1955: 187-196 (A. Fábrega Grau, ed.). MadridBarcelona: CSIC. Aurelio Prudencio, Peristephanon. Himnos a los mártires (J.J. O’Donnell, ed.). Michigan, 1993. Peristephanon (M.J. Bayo, ed.). Madrid, 1946. Obras completas de Aurelio Prudencio (J. Guillén, ed.). Madrid, 1950. Ferrer 
Asimismo en las Actas de los mártires, en los sermones de san Agustín, en la obra de Theodorici Ruinart ${ }^{18}$ y en la España Sagrada ( $T$. VIII) del agustino Enrique Flórez. Su culto es tan antiguo que parece que estuvo generalizado por todo el Imperio Romano, figurando en el martirologio jerominiano y en el calendario de Cartago, siendo exaltado por Paulino de Nola, Avito, Venancio Fortunato, Gregorio de Tours, etc. Sin duda, Vicente de Zaragoza se convirtió en el mártir modélico de las persecuciones de Diocleciano, en la imagen simbólica que tratará de ser imitada por otros relatos, algunas toponimias y numerosas festividades.

Su culto rápidamente traspasará las fronteras de la península lbérica, convirtiéndose en uno de los santos mártires más populares de la cristiandad en la alta Edad Media, con prácticas devocionales posteriores en Portugal como protector de los navegantes, en el sur de Italia como santo invocador para los niños huérfanos, y, finalmente, en Francia, Suiza, Bélgica y Alemania, en estos territorios como patrón de los vendimiadores.

La actividad hagiográfica del diácono Vicente de Zaragoza traspasó prontamente el lugar original de su martirio, Valentia, extendiéndose su culto literario y litúrgico gracias a la difusión de una cultura erudita, asequible para el alto clero hispanorromano, concretada en el Liber Peristephanon del poeta calagurritano Prudencio. Asentada la devoción tanto en la ciudad del Turia como en áreas más o menos limítrofes intensamente romanizadas (Sevilla, Córdoba, Toledo), tras la adopción del catolicismo por la monarquía visigoda, la noticia hagiológica y devocional paseó el nombre de Vincentius por las comarcas mediterráneas, levantándose eremitorios, monasterios y pequeñas iglesias de carácter rural en la Catalunya Vella, consolidándose algunos poblamientos anteriores a la conquista islámica (Pinset, Sant Vicenç d'Obiols, D'Enclar, Sant Vicenç dels Horts, Castelar de n'Hug, Gerri).

Tras el naufragio del visigotismo en el año 711, aproximadamente un siglo después una tímida eclosión toponímica, arquitectónica y litúrgica pareció subrayarse junto a los territorios cantábricos dependientes de la monarquía astur. Después, en un proceso colonizador iniciado en los primeros años del siglo IX, algunos enclaves hagiotoponímicos resaltarán la memoria del mártir en Bujedo de Candepajares y Paradela (Burgos), Cervera de Pisuerga (Palencia),

García, F. A. 2008. "Literatura hagiográfica latina en torno a los mártires Vicente, Sabina y Cristeta de Ávila (siglos VII-XI)". Hispania Sacra LX/121: 946.

${ }^{18}$ Ruinart, Theodorici. 1713. Acta primorum martyrum sincera et selecta: 366-371. Amstelaedami: Officina Wetsteniana. 
Lagoa y Monforte de Lemos (Lugo), al tiempo que en un eje este-oeste se fueron fundando capillas, ermitas e iglesias bajo su advocación (Fisterra, Izal, Cabárceno, Potes, Esles, Lluçà, Saneja, etc.).

La devoción hacia el mártir zaragozano estaba plenamente avalada por una remota tradición. Horas antes de morir el rey Fernando I, el Magno, consciente de su próximo fin, rezó hincado de rodillas ante el altar de San Juan y los santos cuerpos de san Isidoro y san Vicente, mártir de Cristo en Ávila, asimilado en la Crónica Silense y en la Crónica Najerense (III, 12) con el diácono fallecido en Valencia el 22 de enero de 304.

Sus milagros eran conocidos, relacionándose con las afecciones neurológicas, las parálisis y las artrosis, siempre dentro de cierta vaguedad en la descripción realizada por los autores medievales. El prestigio sagrado estaba plenamente fundamentado ya en tiempos visigodos. Enfermo, san Isidoro fue llevado para un ceremonial funerario a la basílica de San Vicente de Sevilla. Terminado el rito se le trasladó a su celda, donde murió al cuarto día siguiente al acto de penitencia en el año 636. "Llegado a los postrero de su edad, que fue muy larga, le sobrevino una muy grave y mortal fiebre. Visto que se moría hízose llevar a hombros por sus discípulos a la iglesia de San Vicente de la misma ciudad de Sevilla; hiciéronle compañía hasta tanto que rindió el alma, un obispo, llamado Juan, y Uparcio, sus muy especiales amigos. En aquella iglesia hizo pública confesión de sus pecados y recibió el Santísimo Sacramento de la Eucaristía, con que por espacio de tres días se aparejó como era razón para partir de esta vida". ${ }^{19}$

Otros milagros fueron espectaculares, especialmente contra aquellos que trataban de arrasar alguna ciudad. El rey de los vándalos Gundérico (406-428) concluyó su vida cuando puso las manos irreverentemente sobre la basílica hispalense, y "al punto murió por juicio de Dios en las puertas del templo arrebatado por un demonio". ${ }^{20}$

Cuando Zaragoza estuvo cercada por los francos, a mediados del siglo VI, una procesión penitencial recorrió la ciudad con la túnica del mártir, describiendo Gregorio de Tours cómo una multitud de hombres con cilicios llevaban la preciada reliquia adelantando a unas mujeres que, cubiertas de cenizas y velos negros, clamaban desgarradoramente. Childeberto I trasladó la dalmática a París en el 542, construyendo una

${ }^{19}$ Mariana, Juan de. 1592. Historia de rebus Hispaniae: VII, 133. Toledo: P. Roderici (Historia general de España. Madrid: Tipografía de C. Alhambra, 1852). ed.).

${ }^{20}$ Crónica Najerense. 2003: I, 142. Madrid: Akal (J. A. Estévez Sola, 
iglesia en honor a san Vicente, conocida luego como Saint-Germain-desPrés. ${ }^{21}$

Un reparto de reliquias y recuerdos del zaragozano se inició tempranamente, desde la presencia de restos en el mausoleo de Gala Placidia (Rávena), representándose a un san Vicente en un mosaico previamente atribuido al diácono oscense Lorenzo, dirigiéndose uno $u$ otro a una parrilla con cuatro ruedas sobre una hoguera encendida. ${ }^{22}$

En el siglo XII sus reliquias llegaron a la catedral de Lisboa, erigiéndose extramuros la iglesia románica de San Vicente, reedificada a partir del año 1582 por mediación de Felipe II como basílica de Sâo Vicente de Fora, mientras que se afirma asimismo que los restos descansaron en Castelo Branco y en la abadía de Saint-Benoît de Castres en el año 864. Parece ser que algunos huesos del santo fueron recogidos clandestinamente por un monje de la abadía de Conques para trasladarlos definitivamente a Castres. ${ }^{23}$

Las ciudades italianas de Vicenza, Cremona, Como (abadía de San Vicenzo de Galiano) y Bari se precian también de poseer varias reliquias del santo, repartidas tras la muerte del obispo de Valencia en el año 1104 tras un viaje a Tierra Santa y un repentino deceso en Bari. La catedral de San Mateo (siglo XII), en Salerno, presume de guardar en su cripta el cuerpo del mártir en una pequeña urna, Corpus S. Vincentii Mart. Dudosas reliquias para mayor realce de iglesias y monasterios, variados y múltiples huesos y artilugios del diácono Vicente proliferaban de forma sorprendente en distantes lugares y distintos tiempos: un hueso desaparecido, "un gran tros del os de la cuxa del benaventurat martyr sant Vicent" donado al monasterio de La Roqueta por la viuda del rey Martín el Humano, otro hueso conservado en un relicario neoclásico en la parroquia de San Valero y San Vicente, en el valenciano barrio de Russafa, o una cadena custodiada en el convento de agustinas de San José y Santa Tecla de Valencia.

La dedicación monumental y litúrgica a san Vicente apareció ya en documentos procedentes de algunos diplomas de Cardeña, en los años $945,963,969$ y $1039,{ }^{24}$ algunos con invocaciones falseadas a un Sancti

${ }^{21}$ Saxer, V. 1900. "Lieus de culte de Saint-Vincent en France avant l'an mil". Bulletin de la Société des Monuments Historiques de L'Yonne 7: 1-12.

22 Duchet-Suchaux, G. y Pastoureau, M. 1996. Guía iconográfica de la Biblia y los santos: IX-X. Madrid: Alianza Editorial. Karutheimer, R. 1984. Arquitectura paleocristiana y bizantina: 214. Madrid: Cátedra.

${ }^{23}$ Forichon, R. 1980. "L'église de Saint-Vincent de Castres". Revue du Tarn 100: 521-527.

${ }^{24}$ Serrano, Luciano. 1910. Becerro gótico de Cardeña: docs. 15, 39, 212, 276 y 335 . Valladolid: Tipografía Cuesta. 
Vincentii levite y algunos apóstoles, fenómeno relativamente común durante los siglos medievales y modernos pues como resultado material y mental la hagiografía actuaba como un instrumento de evangelización dirigido a los sectores populares al utilizarse como propaganda el depósito de reliquias variadas para respaldar la categoría eclesiástica y litúrgica de un determinado templo.

Los ejemplos son numerosos. ${ }^{25}$ En el "Libro del Beçerro de 1676", procedente del monasterio de canónigos premonstratenses de San Miguel de Villamayor de Treviño (Burgos), se señala que en su dependiente monasterio de San Cebrián, en Padilla de Abajo, al oeste de la capital burgalesa, hacia el año 1054 se guardaban, entre otras, las reliquias de los santos Cebrián, Vicente, Esteban, Pelayo, Justo y Pastor, indicándose por otra parte que a mediados del siglo XVII la iglesia citada se encontraba "tan pobre y con tan poca decencia que avn no tiene forma razonable de hermita...": In Christi nomine, et indiuidue trinitatis, vobis dilectisimis sanctos gloriosisque martiribus nobis que post Christum Jesum fortissimis patronis sancti Cipriano, sancti Vicenti, sancti Stephani, sancti Victores et sancti Pelagis seu sanctorum Justi et Pastoris quórum reliquie in han venerabiles ecclesiam recondite esse videntur in locum qui nuncupatur Patella, territorio Castrocirici, procul a flumine Pisorica". ${ }^{26}$

En la iglesia de Sant Vicenç de Besalú, del siglo X, una lauda sepulcral realizada por el maestro gerundense Pere Oller (1420-1430) recuerda el traslado de algunas reliquias del diácono zaragozano hasta las riberas del río Fluvià, mientras que el la seo zaragozana se guardaba una imagen del mártir con algún trozo de sus huesos y un dedo aún cubierto de carne, de acuerdo con unos testimonios de Enrique Cock, notario apostólico de Felipe II en 1585, y del cosmógrafo portugués Juan Bautista Labaña a principios del siglo XVII. En el retablo mayor de la catedral, iniciado en el año 1434 por los maestros Pere Johan y Hans Piet d'Anso, se cobijan en el banco unos relicarios de plata donados por el papa Pedro de Luna, Benedicto XIII, con las testas de los santos Valero, Lorenzo y Vicente, una orfebrería procedente de Avignon.

En el País Vasco y en Galicia surgen algunos recuerdos martiriales relacionados con este santo. En Vitoria, otro templo dedicado a san

25 Vid. Ferrer García, F. A. 2012. Hagiotoponimía, poblamiento y religiosidad en la Edad Media (En torno a los santos Vicente de Zaragoza y Vicente de Ávila). Madrid: en prensa.

${ }^{26}$ Archivo Histórico Nacional. Clero secular-regular. Libro 1.375 (Códice 998), Svumario de la Fundación y Antigüedad, de las Donaciones, Bullas, priuilegios, juros... de este conuento de San Miguel de Triuiño, de el orden de nuestro padre S. Noberto, fol. 13. Transcripción: Proyecto CRELOC-C. Jular ICSIC. 
Vicente, una iglesia columnaria gótica con algunos planteamientos renacentistas que encierra en una capilla lateral algunas reliquias del diácono del obispo Valero. ${ }^{27} \mathrm{Y}$ en San Vicenzo de Cespón, aldea de Boiro (A Coruña), en la iglesia de origen románico se mantiene una tradición que recuerda cómo a finales del siglo XVIII llegó a la parroquia una reliquia de san Vicente, una tibia venerada ocasionalmente por los vecinos cuando el cura párroco muestra el relicario de plata.

Sin embargo, a medida que se va superando el "otoño de la Edad Media" y la modernidad se va asentando en Europa occidental, el culto a san Vicente de Zaragoza (o Valencia) decae alarmantemente, aunque, eso sí, multiplicándose artificiosamente el número de sus reliquias tanto en España como en el resto de Europa.

Con un fuerte sentido supersticioso, a partir de un suceso legendario relativamente reciente, la pequeña localidad alavesa de Nubilla, junto a Pobes, se vanagloriaba de poseer el cuerpo vestido de un san Vicente mártir trasladado desde las catacumbas romanas gracias a la compra realizada en 1784 por un tal Tomás Ortiz de Landazuri, entonces miembro del Consejo de Indias. Algunas informaciones recogidas mencionan que, por miedo, un cura hace años se negó a oficiar la conmemoración del 22 de enero, mientras que de nuevo la tradición local señala cómo la sorprendente reliquia, la figura del mártir recostada como el famoso doncel sengontinense, llegó a otra localidad el 24 de septiembre de 1911 cuando fue trasladada del pueblo cercano de Nubilla a la fría iglesia de Lasierra. A principios del siglo XIX, los seis vecinos de Nubilla "en la iglesia dedicada a la Natividad... veneraban el cuerpo de san Vicente con aprobación del ordinario...." ${ }^{28}$

La llegada a la ciudad de Ávila de las supuestas reliquias localizadas en Leiden y entregadas por el obispo Groisbeeck como insigne y precioso objeto (insigne et pretiosum munus) se debió, probablemente, a la confusión que el duque de Alba tenía entre dos mártires del mismo período (siglo IV), uno el santo exaltado por Prudencio, otro, casi desconocido aunque popular en la diócesis de Ávila, el mártir Vicente, patrón y santo titular de la ciudad con sus hermanas Sabina y Cristeta.

Años más tarde, a principios del siglo XVII, los cronistas abulenses reseñarán cómo en la catedral se conservaba el cuerpo de san Vicente, evidentemente una amplificación, una exageración intencionada a partir

27 Apraiz Buesa, Á. de. 1941. "Imágenes relicarios de la parroquia de San Vicente Mártir de Vitoria y otros lugares". Revista Ateneo 15: 21-29.

${ }^{28}$ Real Academia de la Historia. 1802. Diccionario geográfico-histórico de España: II, 169. Madrid: Imprenta de la viuda de D. Joaquín Ibarra. 
del depósito de un diente y un maxilar procedentes de la ciudad holandesa, mientras que fray José de Sigüenza escribía en su discurso $\mathrm{XVI}$ la presencia en el monasterio de San Lorenzo de "un brazo fuerte, jamás torcido, de san Vicente, mártir español natural de Huesca".

El brazo izquierdo se conserva desde el año 1970 en el ábside de la seo valenciana. El miembro, parece ser, iba a ser trasladado a Jerusalén por el obispo Teudovildo en 1104. Súbitamente enfermo, el prelado depositó la reliquia en la catedral de San Nicolás de Bari hasta que Pietro Zampieri, de Vigonovo (Venecia), la donó a la capilla de la Resurrección de Valencia.

Cuando se conquistaron las reliquias de Leiden, gracias a la donación de Groisbeeck al duque de Alba, se reanudaron las acciones militares y se impuso un nuevo tributo del 10 por ciento sobre todas las ventas, como la alcabala castellana. A los pocos meses, en 1572, se destruyeron los diques acorralando a los viejos tercios españoles mientras que la marina real era aniquilada en Enkhuizen. Dos años después, los estrategas de Felipe II decidieron asaltar la ciudad para aplastar la rebelión, pues su toma separaría la Holanda septentrional de los puertos de Zelanda. ${ }^{29}$

Los tercios españoles iniciaron un nuevo motín por el impago de sus atrasos. La derrota de las tropas en la ciudad, gracias a la inundación de los "polders", fue resaltada tanto por los Mendigos del Mar como por los vecinos calvinistas a pesar de la grandes pérdidas agrícolas. Como premio a la resistencia de la ciudad, Guillermo el Taciturno, en 1575, concederá a los habitantes de Leiden el privilegio de fundar la primera universidad de la actual Holanda. Unos años después, en 1577 y 1578, los calvinistas se hicieron con el poder en algunas ciudades como Gante, Brujas e Ypres.

\section{EL AFÁN COLECCIONISTA DE FELIPE ॥}

El ideal imperial hispánico de una cristiandad única y unida concluyó en 1648. Lo que tenazmente habían defendido Carlos $\mathrm{V}$ y Felipe II y menos convincentemente sus sucesores abrió el paso a una nueva Europa con unos objetivos y comportamientos bien diferenciados de los españoles. Frente a un nuevo desarrollo económico, eficaz y con un acento más laico que religioso, la corte española, en cambio, se conformó con algunos triunfos espirituales.

29 Parker, G. 1998. La gran estrategia de Felipe II: 236-237. Madrid: Alianza Editorial. 
Parecía evidente la fe del rey prudente por las reliquias, pues éstas acercaban al devoto el mensaje de la salvación eterna. En la España del siglo XVI las reliquias, los milagros y los santos contribuyeron al incremento de las prácticas religiosas, en ocasiones teñidas de caracteres paganizantes, supersticiosos o carnavalescos. Constituían las primeras un objeto de veneración y salvación, inverosímiles, manipuladas alrededor de un intercambio forzoso o de un prestigio social, pero también como símbolos de una piedad.

La veneración de unas reliquias ofrecía una contrapartida, pues la inmortalidad se podía expresar en los restos humanos sacralizados, la resurrección de la carne en su dependencia con Dios. El deseo de sobrevivir a la muerte, el anhelo de asociarse con los muertos, con las almas de los difuntos, se reflejaba en este tipo de culto. Se venía a establecer por medio de los restos una forma de religiosidad ambigua que aproximaba el más allá al más acá, los santos a los hombres, el héroe a la persona concreta, una relación con las potencias sobrenaturales por medio del santo, pues muerto éste, había escrito Gonzalo de Berceo, "facié Dios por él tanto que non serié asmado, I vinién tantos enfermos que farién gran fonssado, / non podríemos los medios de nos meter en dictado" (Vida de santo Domingo de Silos, estr. 537 b-c-d).

Aunque no era un dios pagano, ${ }^{30}$ el santo era promovido a una "heroización", dado que el miedo a la muerte (¿o a los muertos?) era asumido por las reliquias. Los discursos eclesiásticos insistirán en los residuos santos en su papel de recreadores de vida, el propio poder de la santidad, pero subrayando también el drama de la vida corporal: la muerte cristiana es ante todo una muerte subordinada a un fin.

Además, junto a la incorruptibilidad del cuerpo santo, la destrucción o la carnicería ejercidas sobre el cadáver garantizaba ante los feligreses la memoria espiritual del santo. La popularidad y la instrumentalización de la notoriedad de los restos santos permitieron, por

30 De manera constante los historiadores han tratado de plantear la equivalencia entre el santo y el dios pagano. Cfr. Santyves, P. 1907. Essais de mythologie chrétienne: les saints successeurs des dieux, Paris: Nourri. Réau, L. 2000. "Los santos sucesores de los dioses paganos", en Iconografía del arte cristiano. Introducción general: 365-372. Barcelona: Serbal. Mientras, Brown, P. 1981. The culte of the saints. Its rise and function in latin christianity: 7-24. Chicago: University of Chicago Press, se opone a las anteriores interpretaciones marcando el acento de una posible continuidad entre los dioses paganos y los santos cristianos en la persistencia de ciertos cultos funerarios en el mundo mediterráneo. 
otra parte, tanto su culto exagerado como la oficialización del mismo a partir de una "catequesis del miedo". 31

Septiembre de 1598. Ya en su cámara junto al presbiterio de la basílica escurialense, el rey demandó la asistencia de la infanta Isabel Clara Eugenia. Acostumbrada a sus treinta y dos años a la cotidiana presencia de huesos y canillas, cabezas y despojos de santos, vírgenes y mártires, la hija del rey se alarmó ante la constante calentura del padre, su hidropesía, la hinchazón de las piernas y el vientre en medio de una sed que le consumía. Ahí llegaron las reliquias que rodearon el lecho del moribundo, una rodilla con su pellejo del mártir san Sebastián, un brazo del dominico Vicente Ferrer, una costilla del obispo Albano y otras tantas que aparecen en la descripción de fray José de Sigüenza (Discursos $X X$ y XXI).

También eran conocidas sus obsesiones por los cuadros de Hieronimus van Aeken, El Bosco, ${ }^{32}$ la alquimia y la figura del perro negro (el Can Cerbero). Se esperaba algún acontecimiento milagroso, como tantas veces había ocurrido en las mismas estancias con sus hijos. $Y$, en efecto, el monarca había ordenado introducir el cuerpo incorrupto del franciscano Diego de Alcalá en el lecho de su hijo Carlos, circunstancia que sirvió para que Lope de Vega, en 1613, escribiera una comedia en verso sobre la vida de san Diego (ca. 1400-1463). ${ }^{33}$

El valor intrínseco de las reliquias procuraba la recuperación de la salud, el buen desarrollo de la vida humana. En 1587, el joven príncipe Felipe enfermó de sarampión en El Escorial. Para paliar la dura y temible convalecencia del heredero se procedió a colocar en el aposento una espina de la santa corona donada por el papa Sixto $\mathrm{V}$ y a recoger unas reliquias de santa Leocadia procedentes de Mons, la ciudad de la provincia belga de Henao que había sido ocupada por el duque de Alba en septiembre de 1572. Continuador de la corona, Felipe III heredó el poder temporal y la obsesión por el culto a las reliquias, como recordaba el cronista y venerable sacerdote abulense Gil González Dávila:

${ }^{31}$ Ferrer García, D. 2004. Ávila y la literatura del Barroco: 102. Ávila: Institución "Gran Duque de Alba".

32 Obsesión compartida con el padre José de Sigüenza en torno a la obra pictórica de El Bosco, un pintor que, al margen de ciertas consideraciones heréticas, exponía en sus cuadros una interpretación estrictamente teológica y moral en la Pasión de Cristo, las tentaciones de los santos (san Antonio) o los símbolos de la vida (El carro de heno y El jardín de las delicias).

${ }^{33}$ Lope de Vega. Comedias de vidas de santos: la vida de san Pedro Nolasco; san Diego de Alcalá, el Niño Inocente de La Guardia, los mártires de Madrid y tres obras más. Madrid (ed. M. Menéndez Pelayo) 1965; San Diego de Alcalá. 1988. Hardcover: ed. T.E. Case. 
... Y salió en esta veneración tan gran discípulo el príncipe, que dice García de Loaisa que, estando en el Escorial, bajaba a visitar las reliquias, y puesto de rodillas y la gorra quitada, después de haverlas adorado, limpiaba el polvo de los vasos que guardaban las reliquias de los santos; y esto fue mucho más, quando llegó a la corona, mostrándose más devoto y mayor venerador de este culto, contra lo que los hereges de nuestro tiempo profesan. ${ }^{34}$

La espiritualidad excéntrica del rey Felipe II explica ciertos comportamientos, pero, por otro lado, una piedad concéntrica en torno al culto de las reliquias sirvió para formalizar en el monasterio de San Lorenzo un variado repertorio necrolátrico, una tesaurización de restos óseos, cenizas y útiles que, en otros casos como parroquias, monasterios y ermitas, suponían un rentable negocio económico a partir de la supervivencia material del santo.

No era este el caso de San Lorenzo de El Escorial, pues el almacenamiento de reliquias implicaba un constante desembolso de las partidas presupuestarias de la Hacienda real. En noviembre de 1585 fue trasladado el cuerpo de Teresa de Jesús desde Alba de Tormes al monasterio abulense de San José, la primera fundación carmelitana. Unos meses después, gracias a las intrigas del tercer duque de Alba, Fernando Álvarez de Toledo, retornó el cadáver a la localidad salmantina. El traslado de reliquias se justificaba en la época por una intervención providencialista, por sus acciones milagrosas y unas cualidades devocionales, subrayando el jesuita y falsario Jerónimo Román de la Higuera que la primera traslación de un cuerpo santo tuvo como protagonista a san Ignacio, el obispo arrojado a los leones en Roma en el año 107; sus huesos fueron depositados en Antioquía (y luego en Roma, otra vez).

Además de la conquista por vía militar o diplomática de numerosos relicarios, los obsequios de restos santos complacían especialmente al rey, iniciándose todo un ceremonial con la presencia de ciento cuarenta frailes jerónimos para recibir un cargamento de reliquias procedente de Alemania en 1598.

Los príncipes extranjeros conocían el fervor filipino. Francisco de Médicis, en 1583, donó sangre del diácono san Lorenzo dentro de una arqueta de lapislázuli, oro, plata y cristal de roca. Felipe II, en 1594,

${ }^{34}$ González Dávila, Gil. 1771. Monarquía de España. Historia de la vida y hechos del ínclito monarca, amado y santo don Felipe Tercero...: 19. Madrid: [s.n.]. 
había emitido desde San Lorenzo de El Escorial una cédula acerca de la entrega del cuerpo del primer obispo abulense, san Segundo, recalcando que las fiestas en su honor estuvieran encaminadas a la veneración y exaltación del santo y no a profanidades. ${ }^{35}$

En un ambiente de extrema inestabilidad por la aparición de unos pasquines difamatorios contra un nuevo impuesto, el concejo abulense decidió donar un largo hueso del santo, al mismo tiempo que se invitaba al monarca a la traslación de las reliquias del prelado a la catedral. Se trataba, por otra parte, de resolver un conflicto de intereses entre la monarquía y el regimiento: en 1592 había sido decapitado don Diego de Bracamonte por su oposición a los millones. Desde la corte madrileña, el rey trataba de recabar informaciones sobre las reliquias de santos concediendo fuertes sumas al abogado Lauvenbech, al jesuita Diego de Salazar, al agustino Baltasar Delgado o al cronista Ambrosio de Morales en sus peregrinaciones por los territorios de la monarquía católica. ${ }^{36}$

Asimismo la preocupación de Felipe II por esqueletos, fragmentos óseos, vestiduras santas, objetos litúrgicos y otros le impulsó a incluir en las "Relaciones topográficas" (1575) una pegunta específica al respecto. ${ }^{37}$ Los vecinos de Valtablado del Río (Guadalajara) se reunían para reverenciar las reliquias de san Vicente, hacían las llamadas rogativas para pedir lluvia y sumergían el cráneo del mártir en un pozo durante la ceremonia; se aglomeraban los campesinos de otros lugares con sus cruces correspondientes en el reinado de Felipe II, "con la cual relica tienen muchos pueblos comarcanos gran devoción, y se juntan en romería en dicha iglesia en cada un año, por voto que tienen hecho, un día de letanías, y en tiempos de necesidad de agua concurren otros muchos pueblos a la dicha relica; y se han juntado a veces veinte y nueve cruces con otros tantos pueblos; y juntos sacan la dicha relica y la

${ }^{35}$ AHPAv. Ayuntamiento. C. 14, leg. 2, núm. 2 (1594, septiembre, 3. San Lorenzo).

36 "En la çiudad de Córdoua, siendo el obispo don fray Bernardo de Fresneda de la $\mathrm{Hoz}$, confesor que fue de la magestad católica Philipe $2^{\circ}$ en la sancta yglesia cathedral, fueron hallados los otros tres mártyres hermanos Fausto, Januario y Marçial, martiriçados en aquella çiudad, para cuya guarda mandó labrar vna capilla que fuese custodia de estas sanctas reliquias entre tanto se calificauan. De cuya sancta ynuençión, aviendo dado quenta a su majestad, mandó a Ambrosio de Morales, su cronista y grande ynquiridor de antigüedades, natural de aquella çiudad, fuese a ella y averiguase y sacase a luz todo lo que pudiese, como lo hizo... En este sancto conzilio se calificaron los tres cuerpos sanctos y mandaron venerar en veynte y tres de henero, día del glorioso san Yllefonso, arçobispo de aquella çiudad, el año de 1583", APSV. Discurso sobre la ynuençión..., fol. 9.

37 Salomon, N. 1973. La vida rural castellana en tiempos de Felipe II. Barcelona: Planeta. 
llevan con gran veneración y reverencia, y la llevan a una fuente y la bañan y ha seído la voluntad de nuestro Señor que mucha veces les ha dado mucho agua..." ("Relaciones topográficas": II, 40).

La permisividad del soberano en torno a las falsas reliquias enlazaba directamente con la consideración de esos restos como objetos coleccionables, por encima de su carácter sagrado, en relación asimismo con las numerosas peregrinaciones y las estrategias militares para trasladarlas de unos lugares a otros. ${ }^{38}$

No pareció preocupar en exceso a Felipe II esa multiplicidad de restos santos en su monasterio, acaso porque su práctica devocional se dirigía más a la veneración tributada a un santo que al carácter puramente material de la reliquia. En cualquier caso, dada su abundante falsificación, ligada a fines mercantiles lucrativos y a un ambiente dominado por la superchería, la Iglesia optó por mantener la tradición consolidada, permitiendo el culto de las reliquias falsas para no entorpecer el de las auténticas. ${ }^{39}$

En este sentido, el monarca sentía cierta predilección por las vidas de santos y sus reliquias más melodramáticas, aquellas que ofrecían un contraste evidente en la lucha contra el pecado y el ejercicio de la mortificación más duro. Figuras como san Albano, santa María Egipciaca, san Sebastián, san Lorenzo, santa Leocadia..., eran apasionadamente recogidas, al mismo tiempo que otros personajes secundarios entraban en las capillas escurialenses a partir de unas cualidades santorales que, en la mayoría de los casos, habían quedado calificadas por una muerte cruenta en los primeros tiempos del cristianismo o en los ambientes tardorromano y altomedieval.

Sin embargo, a medida que fueron consolidándose las reglas tridentinas un nuevo modelo de santo se impuso en las sociedades del Antiguo Régimen, desarrollándose un modelo de santidad encabezado por el predicador, el místico, el fundador de órdenes religiosas u por personajes un tanto anodinos a partir de su docilidad y sencillez: una

38 Reinterpretando algunos asuntos recurrentes de la actual narativa sobre la ficción histórica, el profesor Umberto Eco hacía afirmar al historiador bizantino Nicetas Coniates algunas creencias acerca del valor de las reliquias a su interlocutor Baudolino, un campesino fantasioso y embustero: "Muchas reliquias que se conservan aquí en Constantinopla son de origen dudosísimo, pero el fiel que las besa siente emanar de ellas aromas sobrenaturales. Es la fe la que las hace verdaderas, no las reliquias las que hacen verdadera la fe". Eco, U. 2001. Baudolino: 114. Madrid: Lumen.

39 Véase para este aspecto, Toro Pascua, M. ${ }^{a}$ I. 2001. "Las falsas reliquias en la literatura española del Siglo de Oro: a propósito de la polémica erasmista". Via Spiritus 8: 219-254. 
infancia marcada por la honestidad, la mansedumbre y la sensibilidad por lo sobrenatural, una adolescencia calificada por la fortaleza y la castidad, seguida por la obediencia y la humildad en los tiempos juveniles y, finalmente, una senectud, si se llegaba, en que la sabiduría, el entendimiento y el espíritu de oración precedían al óbito del santo.

De manera casi oculta, el santo que se admiraba en los siglos $\mathrm{XVI}$ y XVII encerraba una sociabilidad tras la muerte, no antes, sino cuando sobre el cuerpo muerto se acumulaban unas cualidades únicas, cuatro dotes inaccesibles para el resto de los mortales reseñadas por el obispo Sancho Dávila: la impasibilidad ("calidad y buena disposición por la qual no podrán recibir alteración alguna"), la claridad ("luz y resplandor tan grandes que estos cuerpos dan de sí que en su comparación será escura la del sol"), la agilidad, "en orden al movimiento de los dichos cuerpos, haziéndoles ábiles... que también les abilita para qualesquiera otros mouimientos apresurados", y la sutilidad ("sus cuerpos... lo serán a semejanza de los espíritus, según la subtilidad que estos tienen en orden al mouimiento"). ${ }^{40}$

El desarrollo de una política contrarreformista volcada en su lucha contra la herejía protestante estaba provocando cierto descontrol de la difusión de las reliquias. Como coleccionista privado, en su lipsanoteca del monasterio escurialense, Felipe II recogió restos de Jesucristo: un cabello de su barba, once espinas de la corona, parte de uno de los clavos, pedazos del pesebre y trozos de la columna. Había además fragmentos del Lignum Crucis guarnecidos en oro, plata y cruces preciosas. De la Virgen, trozos de la vestidura, un cabello y un lienzo en el que se enjugaba los ojos ante la cruz.

Eran abundantes los cuerpos enteros, desde alguno de los Niños Inocentes hasta los restos de los mártires de las persecuciones tretárquicas (Constancio y Mercurio) o de san Mauricio. Cabezas, brazos y otros huesos dominaban los altares y relicarios, destacado particularmente las testas de san Lorenzo, Caput sancti Laurentii, san Jerónimo, el obispo y mártir san Blas, Félix y Adaucto, san Hermenegildo y, entre otras más, san Dionisio el Areopagita.

Sentía el rey una particular devoción por una costilla de san Albano, el santo cefalóforo de los primeros años del siglo $\mathrm{V}$, y por aquellas reliquias procedentes de la "era de las persecuciones", los santos Lorenzo, Vicente, Sebastián, Justo y Pastor, al lado de las santas Águeda, Inés y Leocadia.

${ }^{40}$ Dávila, Sancho. 1611. De la veneración que se debe a los cuerpos de los sanctos y a sus reliquias...: III, XI, 349-350. Madrid: Luis Sánchez. 
Así pues, las hazañas militares de los Tercios compaginaron, durante los reinados de Felipe II y Felipe III, el rigor monárquico por el control de un inestable territorio y la incesante apropiación de restos variados para un coleccionismo mortuorio y piadoso que tendrá su máxima expresión en las entregas que entre los años 1572 y 1598 se registran en el monasterio de San Lorenzo de El Escorial, piezas que tras recorrer Italia, Flandes y Alemania llegaban autentificadas al centro imperial para rellenar urnas, relicarios, envoltorios plateados y cofres con más de siete mil restos, doce cuerpos completos, ciento cuarenta y cuatro cabezas y más de trescientas extremidades enteras.

\section{APÉNDICE DOCUMENTAL}

1.

1570, agosto, 30. Leiden.

Archivo Catedralicio de Ávila. Pergaminos. Doc. n. ${ }^{\circ}$ 158. Perg., s. XVI, 150 x 180; latín, sello de cera roja.

Carta del obispo Gerardo de Groisbeeck, de la diócesis de Leiden, donando unas reliquias de san Vicente al tercer duque de Alba don Fernando Álvarez de Toledo.

\section{GERARDUS A GROISBEECK}

Dei et apostolicae sedis gratia Episcopus Leodiensis, Dux Bullonensis, Comes Lostensis, etc. Vniuersis Christifidelibus, has nostras literas inspecturis aut legi audituris salutem in Domino sempinternam. Cum R[everen]dus in Christo nobis fuerit dilectus D[omi]nus Hermanus Raue Abbas monasterij Sancti lacobi ciuitatis nostre Leodiensis, de Conuentus sui consensu Nobis partem ossis maxillaris et dentem Sancti Vincentij Martyris, quae longissimo atq[ue] immemoriali tempore in eodem Monasterio acurate et cum celebri honore et reuerentia habita atq[ue] asseruata fuerant, donauerit. Nos tam insigne et preciosum munus ingenti cum gaudio accipientes, partem ossis maxilaris et dentem supradicta in hac capsula has etiam nostras literas includente quanta maxima potuimus cum reuerentia collocauimus atque ad Illustrisimum et Excellentisimum D[ucem] D. Ferdinandus Aluarez de Toledo, Ducem de Alua, Marchionem de Coria, Comitem de Saluaterra et pro Serenissimo Philippo eius nominis Secundo Hispaniarum et Rege Catholico eiusdem Regis ditionum Inferioris Germaniae patrimonialium. Locum tenentem gubernatorum et capitaneum generalem dono misimus. In quorum fidem 
ac testimonium has nostras literas nostra subscriptas manu sigili nostri muniti secreti apprensione communiri curauimus. Datum in dicta nostra Ciuitate Leodiensi, Anno a Natiuitate Domini Nostri Millesimo Quinzentesimo septuagesimo, mensi Augusti, die tricesima.

\section{Gerardus Ep[iscopu]s Leodiensis [rúbrica]}

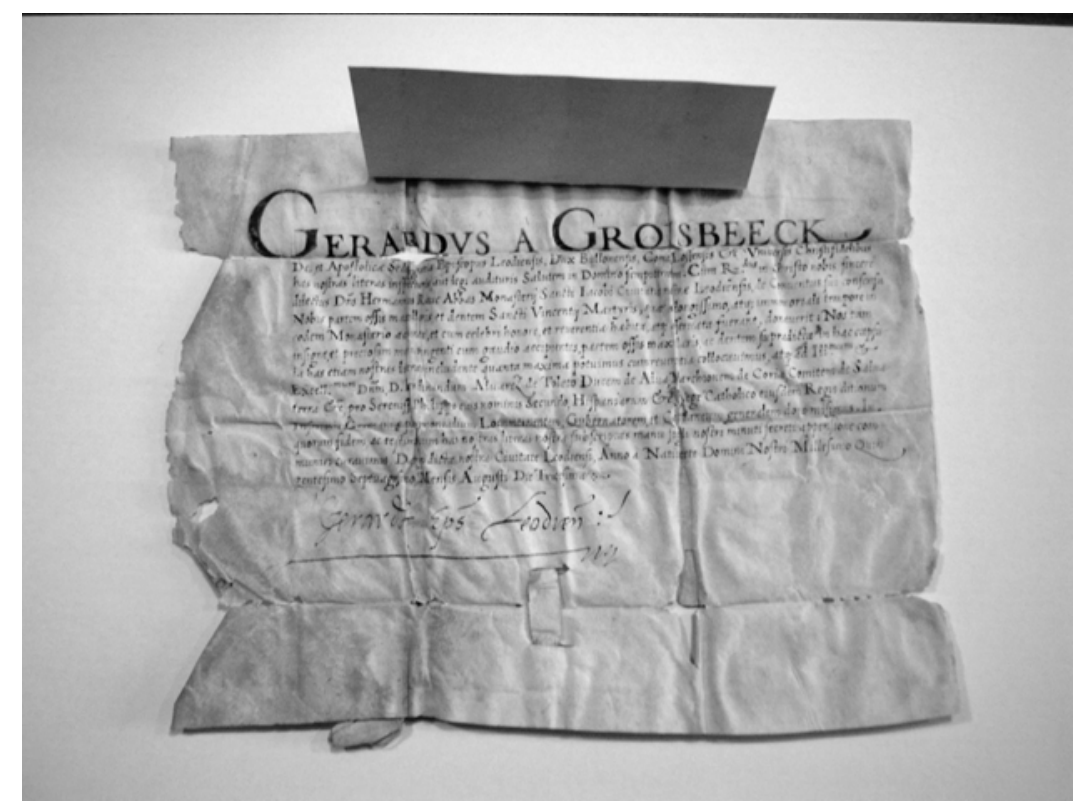

2.

1609, septiembre, 5. Wesaliae.

Archivo Parroquial de San Vicente (Casa Parroquial). Pergamino, s. XVII, 280 x 300; latín, sello de papel sobre cera verde.

Copia auténtica del notario Liberto Melyn sobre la donación de la abadesa del monasterio del Huerto, Wesalia, a Gonzalo de Henao de algunas reliquias de san Ambrosio, san Gregorio y las Once Mil Vírgenes.

Nos Cunnegunda de Rhee monasteri sancti moniarum Horti beatae Marie Virginis, in ciuitate Wesaliensi, ducatus Cluniaec, professa et moderatrix et frater Hermannus Wielich, confessarius et superintendens praedicti monasterii uniuersis et singulis presentes lecturis aut legi audituris salutem et spiritus sancti consolationem precamur nootumque facimus qualiter nobilis ac virtute praeditus deustusque Virgo incalus de Henia, natione hispanus, praefectus tormentorum ciuitatis Rhinberbensis pro catholica maiestate, serenissimis archiducibus Alberto et Isabella, maxima qua erga sanctorum sacra ueneranda pignora deuotione ferebatur, variis preuiis piis requisitionibus nobis factis impeliauit et 
obtinuit sequentes venerandas diorum reliquias uidelicet circulum instar solis circum ornatum particulisque in nominatorum reliquarum de soladitate undecim millium virginum affixis in cuis medio duo parua ossa alterum de sancto Ambrosio, alterum vero de s. Gregorio continentur quas omnes sacras reliquas vitra hominum memoriam in sacrario dicti conuentus hac tenus debito honore conseruatas et cultas ialesque ut hic premominantur reputatas prefato domino in satisfactionem suae deuotionis libere et graciosae donaniminis et realiter consignauimus, in cuis ressidem eis presentibus manu aliena scriptos ego prenomnatus frater Hermanus subscripsi et amb prae sigillo dicti conuentus communiuimus. Datis Wesaliae Cliuorum ipsi die sancti Andae episcopi et martyris. Anno Virginei partus millesimo sexcentesimo nono, sub signatum Hermanus Wielich manu propia et sigillatum predicto sigillo. [rúbrica]

Concordatus suo originale pro me, Libertus Malyn, notarius.

3.

1611, octubre. Tréveris.

Archivo Parroquial de San Vicente (Casa Parroquial). Pergamino, siglo XVII, 2 hoj. in fol., escrito sólo en una; sello de cera verde pendiente (antes pendiente de cordón blanco y rojo).

Copia auténtica del notario Liberto Melyn de la donación hecha por el deán de $\mathrm{S}$. Paulino de Tréveris de la cabeza y huesos de los mártires de la Legión Tebea.

Nos Wilchemus Aberencastelet et caeteri capitulares collegiatae ecclesiae St. Paulini episcopi treuerensis, fidem facimus et presentibus attestamur qua tenus ad instantiam Rd. D. Johannis Ablier, eclesiae metropolitanae coloniensis vicarii, ex parte nobilis et magister Gonsali Guerra de la Vega, deuotionis pietatisque agendae et iurandae causa beneuole dono debbimus unum caput et duo ossa ex societate sanctorum thebanorum in dicta ciuitate Treuerenga pro Christi Dei, nomine martyrio coronatum, quae reliquae in di[cta] [roto] ecclesia moderno tempore, sancto Paulino episcopo, olim vero sanctae genitrici Mariae et martyribus thebais dedicata ab immemorabili tempore a nostris praedecessoribus conseruatae, pro talibus ut supra uere habitae sincere veneratae et cultae fuerunt, imperantes imo procerto habentes, quod dictus D. Gonsalus Guerra de la Vega, secundum suam singularem pietatem et deuotionem quam illum erga sacras reliquas habere inteliximus, easdem ad huiusmodi quam hactenus habitae fuerunt, asseruabuntur et habebuntur, in quorum fidem et testimonium presentes sigillo nostri capituli comunnii et dicti Rd. D. Decani manus subscriptione 
corrobari curauimus. Datum in ecclesia sancti Paulini predicta, anno Incarnationis Dominicae millesimo sexcentesimo undecimo, mensis octobris. Aggi firmado Wilhelmus Berncastel S. Paulini decanus, y sellado con el dicho sello pendiente de cera verde en cordón blanco y roxo.

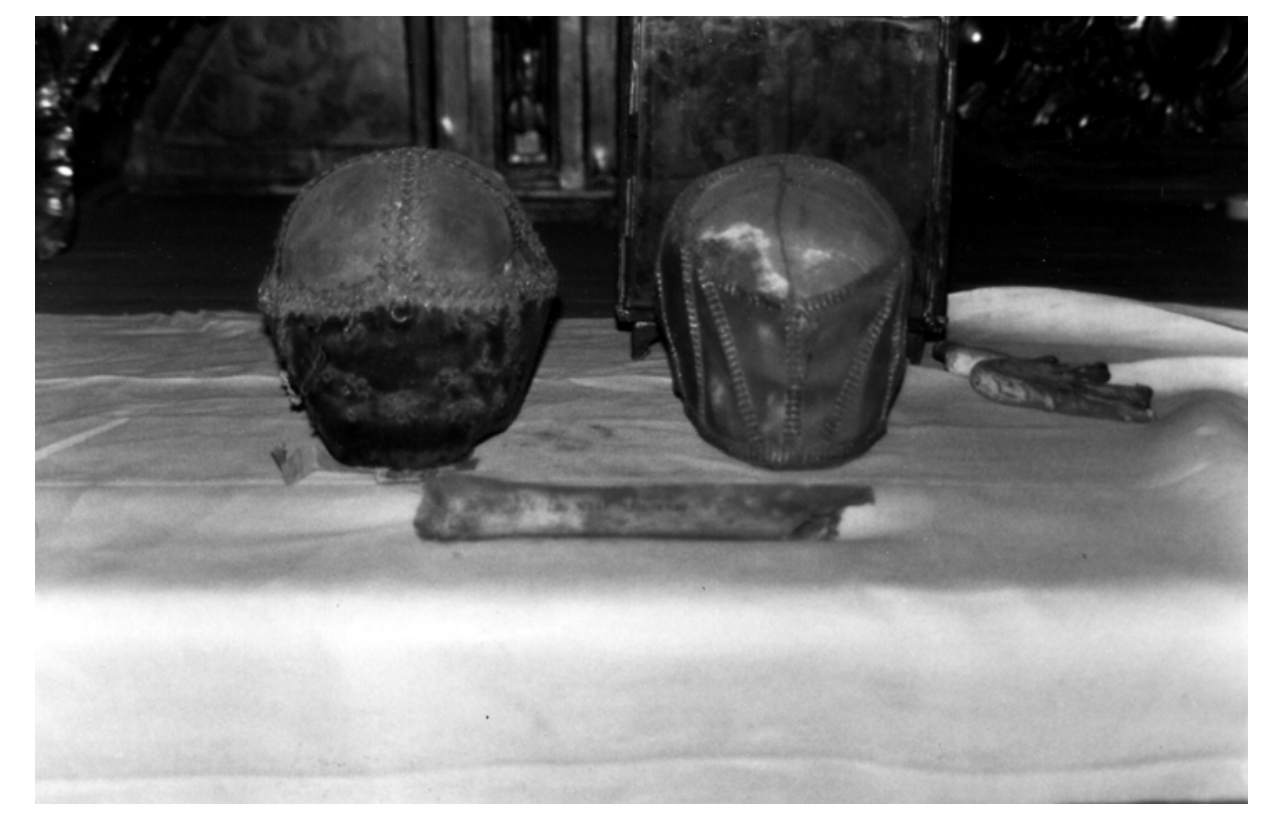

Cabezas de dos mártires tebanos y parte del fémur de una de las Once Mil Vírgenes (cripta de la Soterraña, basílica de San Vicente de Ávila)

\section{BIBLIOGRAFÍA}

Bouza Álvarez, José Luis. 1990. Religiosidad contrareformista y cultura simbólica del Barroco. Madrid: Consejo Superior de Investigaciones Científicas.

Brown, Paul. 1981. The culte of the saints. Its rise and function in latin christianity. Chicago: University of Chicago Press.

Duchet-Suchaux, Gaston y Pastoureau, Michel. 1996. Guía iconográfica de la Biblia y los santos. Madrid: Alianza Editorial.

Ferrer García, David. 2004. Ávila y la literatura del Barroco. Ávila: Institución "Gran Duque de Alba". 
Ferrer García, Félix A. 2008. "Literatura hagiográfica latina en torno a los mártires Vicente, Sabina y Cristeta de Ávila (siglos VII-XI)". Hispania Sacra LX/121: 9-46.

Ferrer García, Félix A. 2009. "Entre el ardor guerrero y el fervor religioso: la vida del capitán Cristóbal de Castro (1545-1585)", en G. del Ser Quijano (ed.), Congreso V Centenario del nacimiento del III Duque de Alba Fernando Álvarez de Toledo. Actas: 547-556. Ávila: Institución "Gran Duque de Alba"-Diputación de Salamanca.

Forichon, Robert. 1980. "L'église de Saint-Vincent de Castres". Revue de Tarn 100: 521-527.

Krautheimer, Richard. 1984. Arquitectura paleocristiana y bizantina. Madrid: Cátedra.

Maltby, William S. 2007. El Gran Duque de Alba. Un siglo de España y de Europa, 1507-1582. Girona: Atalanta.

Parker, Geoffrey. 1998. La gran estrategia de Felipe II. Madrid: Alianza Editorial.

Réau, Louis. 2000. Iconografía del arte cristiano. Introducción general. Barcelona: Serbal.

Ruiz-Ayúcar Zurdo, M. ${ }^{a}$ Jesús. 1998. "Reliquias y relicarios. El legado de don Sancho Dávila y Toledo", en M. ${ }^{a}$ Mariné, Homenaje a Sonsoles Paradinas: 231-245. Ávila: Asociación de Amigos del Museo de Ávila.

Salomon, Nöel. 1973. La vida rural castellana en tiempos de Felipe II. Barcelona: Planeta.

Sanz Hermida, Jacobo. 2001. "Un coleccionista de reliquias: don Sancho Dávila y el Estudio Salmantino". Via Spiritus 8: 59-93.

Saxer, Victor. 1900. "Lieus de culte de Saint-Vincent en France avant l'an mil". Bulletin de la Société des Monuments Historiques de L'Yonne 7: 1-12.

Tervarent, Guy de. 1930. La légende de Sainte Ursule dans la littérature et dans l'art du Moyen Âge. Paris: Les Éditions G. van Oest.

Thomas, Keith. 1991. Religion and the decline of magic. Studies in popular beliefs in Sixteenth and Seventeenth-century England. London: Penguin Books. 
Toro Pascua, M. ${ }^{\text {a }}$ Isabel. 2001. "Las falsas reliquias en la literatura española del Siglo de Oro: a propósito de la polémica erasmista". Via Spiritus 8: 219-254.

Wessels, Leonardo H. M. 1999. "Tirano o soberano. La imagen cambiante de Felipe II en la historiografía holandesa desde Bor hasta Fruin (siglos XVI-XIX". Cuadernos de Historia Moderna 22: 157-181. 